\title{
CIHR hikes grants to young researchers
}

$\mathrm{R}$ esponding to protests from scientists and 15 university presidents, the Canadian Institutes of Health Research (CIHR) has pledged at least $\$ 30$ million for junior scientists in the 2016 Project Grants competition. This amounts to about $10 \%$ of its total grant money. CIHR has also agreed to a moratorium on any further reforms beyond the highly controversial suite of changes it introduced in 2014.

The pledge to halt further reforms comes at the request of the university presidents. In an open letter citing "serious concerns among members of the Canadian research community" and "many unanswered questions and areas of concern," the presidents also asked CIHR to submit its reforms to an independent international review and to convene a national health research summit to discuss them.

The CIHR rejects both ideas, said Peggy Borbey, director general of CIHR's Investigator-Initiated Research Branch. The university presidents declined CMAJ's request for an interview.

The decision to earmark funds for junior scientists or early-career investigators (ECIs) recognizes that they were underfunded in CIHR's most recent Foundation Scheme funding round, Borbey said.

"We received a troubling signal about the future of research and we want to address it," Borbey added. "We now expect that ECIs will do very well in the next round."

The Association of Canadian Early Career Health Researchers, a group of 110 ECIs, looked at past funding and concluded that ECIs have typically received approximately $18 \%$ of research funding each year.

But last year, after CIHR transferred $45 \%$ of its grants budget to its new Foundation Scheme, ECIs received just $5 \%$ of the funds awarded, says Michael Hendricks, a neuroscientist at McGill University in Montréal who leads the ECI association.

In part, this is because CIHR has abandoned reviews of funding proposals by panels of scientists "who actively promoted new investigator success" in favour of online reviews, said Hendricks. The success rate in the most recent funding competition was $4 \%$ for ECIs, compared with $25 \%$ for established investigators.

Borbey said CIHR has not changed its funding review process for the upcoming round of grants despite the criticisms. She was unable to confirm that the new earmarked money will fully restore the proportion of funding historically allotted to ECIs.

Hendricks says the $\$ 30$ million pledged for ECIs in CIHR's project grants competition is inadequate. "The cohort of ECIs now starting independent careers have had half the normal number of opportunities to obtain their first operating grant due to cancelled competitions, while success rates are the lowest in CIHR's history," he said. "If this continues, it will have a crippling impact on the future of Canadian health research."

"CIHR is the only major health research agency in the world whose current granting system awards systematically smaller grants to earlycareer investigators."

CIHR is tracking funding outcomes closely in the piloted reforms, and will adjust accordingly, Borbey says

In a recent presentation at the Academic Health Sciences Network Symposium in Ottawa, CIHR President Dr. Alain Beaudet traced the reduction in funding for ECIs to demographic changes among Canadian scientists. "Young researchers are being stalled by demographic factors, and namely the fact that senior researchers are staying productive in research longer and are retiring later."

Hendricks rejects this justification. "What CIHR has done is massively increased the dollars-per-scientist among established investigators by cutting dollars-per-scientist to early- and mid-career investigators. No demographic shift justifies this."

His group proposes equalizing success rates and dollar allocation proportionately across the three career stages. - Paul Webster, Toronto, Ont.

CMAJ 2016. DOI:10.1503/cmaj.109-5277 